\title{
CELEBRACJE WIELKIEGO TYGODNIA TRADYCJI ZACHODNIOSYRYJSKIEJ W KOŚCIELE SYROMALANKARSKIM W INDIACH
}

Chrześcijaństwo syryjskie w Indiach szczyci się starożytnym pochodzeniem. Bez względu na nikłą możliwość historycznej weryfikacji jego początków z całą pewnością możemy przyjąć, że pojawiło się ono tam we wczesnym stadium rozwoju Kościoła. Według niektórych badaczy zostało przyniesione do Indii przez św. Tomasza Apostoła ok. 52 r. n.e., $z$ kolei inni wolą widzieć jego początki w przybyciu grupy perskich uchodźców pod wodzą niejakiego kupca Tomasza ${ }^{1}$. Jakkolwiek nie spojrzeć na genezę indyjskiego chrześcijaństwa, należy stwierdzić, że jest ono jedną $\mathrm{z}$ najstarszych denominacji.

* Ks. Mateusz Potoczny, dr kościelnych nauk wschodnich w zakresie liturgii (PIO, Rzym), prezbiter diecezji opolskiej, birytualista, pracownik naukowo-dydaktyczny w Katedrze Liturgiki, Obrzędowości i Hagiografii Wydziału Teologicznego Uniwersytetu Opolskiego (mpotoczny@uni.opole.pl).

1 Por. P. Pallath, La Chiesa cattolica in India, Roma 2003, s. 3; A. Attiya, Historia Kościołów Wschodnich, Warszawa 1978, s. 311. 
Wieki trwania i ciągłego rozwoju chrześcijaństwa w kontekście indyjskim zaowocowały powstaniem wielu jego odmian, które zachowując liturgiczną tradycję przyniesioną niegdyś z Bliskiego Wschodu, wykształciły zupełnie wyjątkowe zwyczaje i obrzędy². Wynika to zresztą z przyjętego przez indyjskich chrześcijan tradycji syryjskich aksjomatu, zgodnie z którym określają oni siebie jako „hinduistyczni w kulturze, chrześcijańscy w religii i orientalni w kulcie” ${ }^{3}$. Do tych oryginalnych dla indyjskiego chrześcijaństwa obrzędów liturgicznych z całą pewnością należy zaliczyć celebracje najważniejszego w roku tygodnia, określanego w literaturze mianem wielkiego i świętego.

W niniejszym studium zaprezentowane zostaną osobliwości Wielkiego Tygodnia spotykane dziś w należącym do tradycji zachodniosyryjskiej Kościele Syromalankarskim. Refleksja opierać się będzie na analizie praktyk spotkanych w trzech miejscach katolickiej archidiecezji Thiruvalla w stanie Kerala: parafii w Kottayam, parafii w Anchery oraz w aśramie na Górze Krzyża (Kurishumala) ${ }^{4}$.

\section{WIELKI TYDZIEŃ W KOŚCIELE SYROMALANKARSKIM}

Podobnie jak we wszystkich innych wspólnotach chrześcijańskiego świata, celebracje Wielkiego Tygodnia wśród syryjskich chrześcijan Indii wzorowane są na liturgii jerozolimskiej. Każdy dzień tego wyjątkowego tygodnia poddaje medytacji inne wydarzenie paschalne związane z osobą

${ }^{2} \mathrm{O}$ niektórych $\mathrm{z}$ nich pisaliśmy już na łamach niniejszego czasopisma. Zob. M. Potoczny, Kościół dla wybranych? O specyfice indyjskich chrześcijan knānāya, „Teologia i Człowiek" 28 (2014) 4, s. 237-257.

3 P. J. Podipara, Hindu in Culture, Christian in Religion and Oriental in Worship, „Ostkirche Studien” 8 (1959), s. 82-104. Por. P. Pallath, La Chiesa, s. 34-35; C. D. Sebastian, Saint Thomas Christians of India: A Paradigm of Cultural Identity in the Eastern Christianity, w: Philosophy, Religion, and Culture of Asian Countries, ed. S. Pakhomov, Saint-Petersburg 2009, s. 130-137.

${ }^{4} \mathrm{~W}$ tym miejscu pragnę wyrazić wdzięczność ks. dr. Jacobowi Thekeparampilowi, dyrektorowi Ekumenicznego Instytutu Badawczego Świętego Efrema w Kottayam, jego zastępcy ks. dr. Rajowi Parakottowi oraz czcigodnym mnichom z aśramu w Kurishumala za umożliwienie mi w latach 2013 i 2017 uczestnictwa w syromalankarskich celebracjach Wielkiego Tygodnia. 
Jezusa Chrystusa i wprowadza wiernych w jego przeżywanie. Zgodnie ze starożytna tradycją Kościołów syryjskich w większość dni Wielkiego Tygodnia nie sprawuje się tam qurbānā, czyli ofiary eucharystycznej. Rubryki jasno określają, że tę należy sprawować jedynie w Wielki Czwartek i w Wielką Sobotę ${ }^{5}$. Chociaż Kościół Syromalankarski jest częścią rzeczonej tradycji liturgicznej syryjskiego Zachodu, to jednak w jego aktualnej praktyce tam, gdzie obecny jest kapłan, Eucharystię sprawuje się w każdy dzień Wielkiego Tygodnia ${ }^{6}$. O tym, że praktyka codziennej celebracji nie należy do tradycyjnego depozytu liturgii świadczy fakt, że większość najistotniejszych tekstów liturgicznych odnoszących się do poszczególnych wydarzeń paschalnych odczytywana jest w ramach godzin kanonicznych, w których indyjscy wierni uczestniczą nie tylko chętnie, ale również aktywnie. Biorąc udział we wspólnym odmawianiu liturgii godzin we wspólnocie malankarskiej, można odnieść wrażenie, że nie ma tam miejsca na jakąkolwiek formę biernego uczestnictwa: każdy wierny staje się bowiem autentycznym „koncelebransem”, czynnie biorącym udział w odmawianiu modlitw, śpiewie hymnów czy wykonywaniu gestów ${ }^{7}$. Dzięki takiej formie pełnego uczestnictwa w celebracjach liturgicznych wierni od najmłodszych lat zaznajamiają się z teologią każdego dnia Wielkiego Tygodnia. Przepisane na ten czas hymny liturgiczne, odśpiewywane przez wielu uczestników liturgii z pamięci w ojczystym języku malajalam, niosą bowiem głębokie treści chrystologiczne, oparte na fundamencie prorockich zapowiedzi Starego Testamentu. Warto dodać, że wielkotygodniowa liturgia godzin w Kościele Syromalankarskim posiada tę samą strukturę co w innych okresach roku i składa się z siedmiu godzin. Są to, poczynając od pierwszej, ramšo odmawiane wieczorem dnia poprzedzającego, sutōrō, lilyō z czterema qaume, poranne saprō oraz odmawiane w ciągu dnia tercja, seksta i nona. Charakterystyczną cechą modlitw odmawianych w tym szczególnym okresie roku kościelnego są liczne prostracje połączone zazwyczaj ze śpiewem antyfony: „Nasz Boże,

${ }^{5}$ B. Varghese, Holy Week Celebrations in the West Syrian Church, w: Hebdomadae sanctae celebratio. Conspectus historicus comparativus, ed. A. G. Kollamparampil, BEL Subsidia 93, Roma 1997, s. 167.

${ }^{6}$ Na przykład we wspomnianej wyżej parafii w Kottayam.

7 Por. B. Varghese, West Syrian Liturgical Theology, Aldershot 2004, s. 144. 
bądź nam miłościw! O Panie, zmiłuj się nad nami” ('Alāhan rahem 'lain, māran 'etraham'lain $)^{8}$.

Zaczerpnięta z oficjum Wielkiego Poniedziałku modlitwa wprowadzająca ukazuje narrację, jaka towarzyszyć będzie modlącej się wspólnocie w ciągu całego tygodnia:

Uczyń nas godnymi, o Panie, uczestnictwa w Twojej życiodajnej Męce. Pozwól nam naśladować Twe uniżenie dla nas i stać się dumnymi z Twego za nas ukrzyżowania; ulecz nas bliznami cierpienia, które zniosłeś dla naszego zbawienia oraz pozwól żyć dzięki Twej śmierci, która znosi nasząa .

Wierni omawianej indyjskiej wspólnoty kościelnej w rzeczywistości rozumieją zawarte w powyższej modlitwie wezwanie w sposób bardzo literalny. Zarówno liturgia, jak i wielkotygodniowe zwyczaje mają tu bowiem niezwykle dramatyczny wyraz i zyskują oryginalny indyjski koloryt. Chociaż szczegółowe kwestie zostaną omówione w dalszej części niniejszego studium, to już w tym miejscu warto zwrócić uwagę na kilka przykładów. Pierwszy dotyczy muzycznego wymiaru oficjów: w Wielkim Tygodniu w orientalnych wspólnotach chrześcijan indyjskich nie mają zastosowania tony ochtoechos ${ }^{10}$, gdyż liturgia ta posiada własne melodie, wyrażające głęboki smutek i żal ${ }^{11}$. Ponadto w omawianych obrzędach wstępny i końcowy trishagion $^{12}$ zastąpiony jest specjalną wielkotygodniową doksologią chwały. Należy dodać, że wszystkie modlitwy w szczególny sposób koncentrują się na osobie Jezusa Chrystusa i na Jego męce. W omawianym okresie nie ma żadnych obrzędów ani hymnów lub modlitw adresowanych do Najświętszej Maryi Panny, świętych lub modlitw za zmarłych, choć w tym

8 A. Konat, ktābā d-taksā d-husāye d-shabtā d-hashā pārukāyā da mshiā alāhan, Pampakkuda 1958, s. 6.

${ }^{9}$ F. Acharya, Prayer with the Harp of the Spirit. The Prayer of Asian Church, t. 3, Kurishumala 1985, s. 379; A. Konat, ktābā d-taksā d-husāye, s. 1.

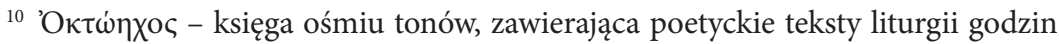
podzielonych na osiem tygodni, $\mathrm{z}$ ośmioma różnymi tonami muzycznymi.

11 B. Varghese, Holy Week Celebrations, s. 167.

12 Tpıбá $ı$ เov - śpiew liturgiczny zaczerpnięty z Iz 6,3, wysławiający Trójcę Świętą, obecny we wszystkich tradycjach liturgicznych, zwłaszcza w przestrzeni chrześcijańskiego świata orientalnego. 
ostatnim przypadku wyjątek stanowią czwartek i sobota (o czym poniżej). Dodatkowo, zgodnie z przepisami liturgicznymi, w Wielkim Tygodniu nie przewiduje się pocałunku składanego na krzyżu, księdze Ewangelii bądź ręce kapłana ${ }^{13}$.

Wśród wielkotygodniowych celebracji znajdujemy jeszcze jedną, którą - chociaż nie jest już sprawowana - wciąż odnajdujemy w syromalankarskich księgach liturgicznych. Chodzi tu o „Obrzęd wejścia do nieba”, przepisany na wieczór Wielkiego Poniedziałku. Ów ryt zwyczajowo składał się z serii modlitw połączonych ze swoistym misterium liturgicznym opartym na ewangelicznej przypowieści o dziesięciu pannach (por. Mt 25,1-13). Ten liturgiczny performance rozpoczyna się procesją, w której wierni i duchowieństwo udają się do drzwi kościoła. Odmawiane tam modlitwy połączone są z potrójnym uderzeniem krzyżem $\mathrm{w}$ drzwi kościoła. Obrzęd ten przypomina bizantyjski zwyczaj otwarcia świątyni praktykowany w wielkanocny poranek. Ponieważ wspólnoty indyjskie zrezygnowały z tej celebracji, pominiemy tu jego szczegółową prezentację ${ }^{14}$.

Zanim przejdziemy do omówienia charakterystycznych wielkotygodniowych celebracji Kościoła Syromalankarskiego, należy najpierw odwołać się do innego ważnego obrzędu, który choć odprawiany dokładnie w środku Wielkiego Postu, to jest silnie związany z omawianymi tu obrzędami. Chodzi to o obrzęd „podwyższenia Krzyża”, który mimo że znany jest wśród wszystkich wspólnot zachodniosyryjskich, to jednak w Indiach zyskał nieco inny charakter. Dzień jego celebracji jest stały, tj. środa - 25. dzień Wielkiego Postu. Tego dnia podczas modlitwy pierwszego qaumā kapłan ustawia drewniany krzyż pośrodku świątyni na stojaku zwanym $m n a \bar{r} t h \bar{a}$. Ten sam krzyż używany będzie podczas uroczystych celebracji Wielkiego Piątku i Niedzieli Zmartwychwstania. Stojak przykryty jest czerwonym płótnem, w Niedzielę Palmową zaś zmienia się je - podobnie jak kurtyny sanktuarium - na płótno koloru czarnego. Z obydwu stron stojaka umieszcza się dwie świece, które w większości indyjskich parafii zamienione zostały na elektryczne żarówki koloru czerwonego, często migające (sic!). Podczas obrzędu „wywyższenia krzyża” antycypuje się ceremonie, w których wierni uczestniczyć będą w Wielkim Tygodniu,

${ }_{13}$ Por. F. Acharya, Prayer with the Harp, s. 377-378.

14 Więcej zob. B. Varghese, Holy Week Celebrations, s. 171-175. 
strukturalnie bowiem jest on podobny zarówno do rytów Wielkiego Piątku, jak i Wielkanocy. Kapłan w procesji dookoła kościoła niesie ów krzyż, po czym błogosławi cztery strony świata. Ustawiony pośrodku nawy krzyż jest obiektem szczególnej czci wiernych, staje się wręcz przedmiotem ich autentycznej adoracji. Symbolika tego krzyża związana jest zarówno z wywyższonym przez Mojżesza brązowym wężem (por. Lb 21,4-9), stanowiącym lekarstwo dla ukąszonych na pustyni Izaraelitów, jak i z prefiguracją zbawczego wywyższenia Jezusa Chrystusa ${ }^{15}$.

Warto zauważyć, że w większości syromalankarskich parafii wielkotygodniowe ceremonie sprawowane są w języku malajalam, jednak w przypadku omawianych tu wspólnot z Kottayam, Anchery i Kurishumala wierni przyzwyczajeni są do liturgii odprawianej w języku syryjskim lub nawet angielskim, co czyni z liturgii niezwykle ciekawą mieszankę.

\section{NIEDZIELA PALMOWA}

W większości tradycji liturgicznych celebracje wielkotygodniowych wydarzeń zazwyczaj rozpoczynają się w tzw. Sobotę Łazarza lub w samą Niedzielę Palmową, które to dni z natury swej nawiązują do zmartwychwstania. Aleksander Schmemann zauważa:

„Wypełniwszy czterdzieści dni... chcemy ujrzeć Święty Tydzień Twej Męki”. Tymi słowami śpiewanymi podczas piątkowych nieszporów dobiega końca Wielki Post i wchodzimy w coroczną celebrację pamiątki Chrystusowej męki, śmierci i zmartwychwstania. Zaczyna się to w Sobotę Łazarza. Podwójne święto wskrzeszenia Łazarza i wjazdu Pana do Jerozolimy (Niedziela Palmowa) opisane jest w tekstach liturgicznych jako „początek krzyża” i dlatego powinno być rozumiane w kontekście całości Wielkiego Tygodnia ${ }^{16}$.

I chociaż w większości tradycji Niedziela Palmowa ma szczególne znaczenie pasyjne, wydaje się, że nie jest tak w przypadku liturgii

15 Por. A. Kakkanatt, Christological Catechesis, s. 39-40; P. A. Kadavil, The Syrian Orthodox Church: its Religion and Philosophy, Kottayam 2005, s. 90-91.

16 A. Schmemann, A Liturgical Explanation of Holy Week, http://orthodoxinfo. com/general/a-liturgical-explanation-of-holy-week.pdf (12.04.2017). 
zachodniosyryjskiej. Baby Varghese podkreśla, że zachodni Syryjczycy nie traktują Niedzieli Palmowej jako części Wielkiego Tygodnia, a oficja przewidziane na ten dzień nie przywołują wydarzeń związanych z męką Chrystusa. Jak wiadomo, w innych tradycjach, np. łacińskiej, w Niedzielę Palmową odczytuje się dwie perykopy ewangelijne: pierwszą przed Mszą św., kiedy to przewidziany jest fragment $\mathrm{z}$ uroczystego wjazdu Chrystusa do Jerozolimy (Mt 21,1-11; Mk 11,1-10; Łk 19,28-40), z kolei w trakcie liturgii eucharystycznej czyta się cały opis Męki Pańskiej z Ewangelii synoptycznych zależnie od kolejnego cyklu liturgicznego (Mt 26,14-27,66; Mk 14,1-15,47; Łk 22,14-23,56). Natomiast w tradycji zachodniosyryjskiej Niedziela Palmowa powinna być przede wszystkim antycypacją radości paschalnej, która pozwala wiernym na metafizyczne przejście ponad bólem i ciemnością męki. Vargese zaznacza, że taki właśnie charakter tego dnia wpisuje się w ogólne orientalne rozumienie niedzieli, która nigdy nie była rozumiana jako dzień żałoby, ale zawsze charakteryzowała się radością wynikającą z Chrystusowego zmartwychwstania ${ }^{17}$. Teksty liturgiczne używane w parafiach Kościoła Syromalankarskiego potwierdzają radość, która w Niedzielę Palmową wydaje się o wiele większa niż w jakąkolwiek niedzielę zwykłą. Wystarczy odnieść się tu do sedrā z liturgii tego dnia, które zawiera 22 wezwania, po których następuje zawołanie Hosanna (Ōshana), radośnie wyśpiewane czy wręcz wykrzyczane przez zgromadzonych wiernych ${ }^{18}$.

Oczywiście praktyka liturgiczna jak zwykle jest tu o wiele bogatsza niż teoria. Stąd współcześnie coraz częściej Niedzieli Palmowej, nazywanej przez indyjskich chrześcijan Ōshana Njayarazhcha lub Kuruthola Perun$n a l^{19}$, nadaje się również wymiar pasyjny, spotykany w innych wspólnotach chrześcijańskich. Jeden z syromalankarskich biskupów pisze:

Jest to [niedziela] zmieszanych uczuć bólu i radości; bólu spowodowanego stojącym u drzwi świętym Tygodniem Męki; radości, gdyż jest to pamiąt-

17 Por. B. Varghese, Holy Week Celebrations, s. 165.

18 Por. Holy Liturgy of Passion Week: From Hosanna to Kyoto (Easter), Mississauga 2011, s. 12-13.

19 Por. Palm Sunday (Kuruthola Perunnal), Maundy Thursday (Pesaha), Good Friday (Dukha Veli) and Easter among Saint Thomas Christians of India, http://www. nasrani.net/2007/03/25/passover-among-nasrani-syrian-christians-of-kerala/ (10.02.2017). 
ka chwalebnego wjazdu Jezusa Chrystusa do Jerozolimy w towarzystwie mężczyzn i dzieci nieświadomie wołających „Hosanna!” i wysławiających „Króla Izraela” 20.

W syromalankarskiej tradycji liturgicznej obrzędy Niedzieli Palmowej są niezwykle dostojne. Rozpoczynają się one zazwyczaj od porannej liturgii godzin. Po saprā rozpoczyna się uroczysta procesja, która wyrusza przez drzwi północne. Zgodnie z kulturowym ceremoniałem indyjskim $\mathrm{w}$ procesji niesie się nie tylko świeże liście palmowe, świece, kadzidło i księgę Ewangelii, ale także flagi i kolorowe parasole podkreślające uroczysty charakter świętowanego wydarzenia. Ponadto w parafii w Kottayam podczas procesji główny celebrans niesie także krzyż zrobiony z liści palmowych. Po dojściu przed główne drzwi kościoła procesja się zatrzymuje i odczytywany jest fragment Ewangelii (Mt 21,1-11). Następnie przewodniczący liturgii odśpiewuje szereg wezwań, z których każde kończy się podwójnym zawołaniem Ōshana: kapłan śpiewa je jako pierwszy, sypiąc w kierunku zgromadzonych wiernych liście i kwiaty, na co zgromadzeni wierni odpowiadają, powtarzając zawołanie ${ }^{21}$. Po zakończeniu tej litanijnej formy modlitwy procesja wraca do kościoła, gdzie wszyscy składają przyniesione palmy na wcześniej przygotowanym stole. Rozpoczyna się kolejna część liturgii godzin, po której następuje błogosławieństwo palm, które zawiera nie tylko odniesienia do tych konkretnych roślin, ale do całej natury ${ }^{22}$ :

Panie, Boże zastępów niebiańskich! [...] Teraz, wyciągnij Twą silną, miłosierną i współczującą rękę i pobłołgosław te owce Twej parafii, i złożone przez nami palmy, i drzewa, z których zostały ścięte. Niech te palmy przyniosą błogosławieństwo tym, którzy je będą trzymać.

$[\ldots]$

Panie Boże, który wypełniłeś wśród nas dzieło Twego Wcielenia; teraz, w Twym wielkim miłosierdziu, pobłołgosław te gałązki i drzewa, z których zostały wzięte, i wszelką stworzoną przez Ciebie roślinność. [...]

Panie, przez zamieszkanie Twej łaski pobłołgosław nas, nasze pola, plony

\footnotetext{
20 P. A. Kadavil, The Syrian Orthodox Church, s. 91.

${ }^{21}$ Por. tamże, s. 92.

22 Por. B. Varghese, West Syrian Liturgical, s. 142.
} 
i te gałązki. Uczyń te palmy pobłogosławionymi, aby stały się silnymi dla ochrony naszych domów, oddaliły szatana i wszelkie pokusy ${ }^{23}$.

Po tej modlitwie następuje błogosławieństwo czterech stron świata. Kapłan, trzymając upleciony z liści palmowych krzyż, zwraca się najpierw ku wschodowi, następnie na zachód, północ i południe, powtarzając na przemian z ludem:

Celebrans: Ty, któremu zawsze służą aniołowie!

Lud: Święty jesteś, Boże!

Celebrans: Ty, którego zawsze błogosławią Cherubini!

Lud: Święty jesteś, Wszechmogący!

Celebrans: Ty, którego wysławiają Serafini!

Lud: Święty jesteś, Nieśmiertelny!

Celebrans: My grzeszni w skrusze modlimy się!

Lud: Hosanna Synowi Dawidowemu! Zmiłuj się nad nami ${ }^{24}$.

Uroczyste błogosławieństwo palm kończy się sprawowaniem świętej Qurbānā̄en .

\section{WIELKI CZWARTEK}

Dla wszystkich denominacji chrześcijaństwa zasadniczym elementem wielkoczwartkowych obrzędów jest uroczysta celebra Eucharystii upamiętniającej wydarzenie Ostatniej Wieczerzy Jezusa Chrystusa. Księgi liturgiczne Kościoła Syromalankarskiego ten wyjątkowy dzień nazywają „Czwartkiem Misteriów”26, co wiąże się także z praktykowanym przez większość Kościołów poświęceniem w ten dzień świętego myronu, zwanego na Zachodzie „krzyżmem”. Mimo że w kontekście indyjskim błogosławieństwa oleju można dokonać w dowolnym dniu Wielkie-

${ }^{23}$ Holy Liturgy of Passion Week, s. 24-25; ktābādmáddānā d-hudrā shantānāyā, Andu Thaksā (Suriyani, Malayalam), Puthencurz 2016, s. 224.

${ }_{24}$ Tamże, s. 25-26. Por. A. Kakkanatt, Christological Catechesis, s. 40-41; ktābādmiaddānā, s. 226.

25 P.A. Kadavil, The Syrian Orthodox Church, s. 93.

${ }^{26}$ Zob. Prayers of the Holy Week, ed. B. Varghese, Kottayam 2015, s. 134. 
go Postu, zwyczajowa nazwa „Czwartek Misteriów” cieszy się tu dużą popularnością ${ }^{27}$.

Od strony liturgicznej w interesującym nas kontekście eklezjalnym celebracja obrzędów Wielkiego Czwartku rozpoczyna się odmówieniem oficjum o trzeciej w nocy, po którym następuje Eucharystia ${ }^{28}$. W praktyce prezentowanych w niniejszym studium wspólnot pomija się zarówno nocną modlitwę, jak i sprawowaną po niej Qurbānā.

Następny moment liturgiczny rozpoczyna się w wielkoczwartkowe popołudnie od odmówienia kolejnego zestawu modlitw kanonicznych. Rubryki przewidują w tym miejscu obrzęd obmycia nóg (por. J 13,1-19), jednak dodają, że sprawuje się go jedynie w przypadku, gdy podczas liturgii obecny jest biskup ${ }^{29}$. Mimo tej precyzacji istnieją od niej pewne wyjątki. Na przykład w aśramie w Kurishumala opat dokonuje obmycia nóg wszystkim członkom wspólnoty. Sama ceremonia rozpoczyna się od recytacji bądź śpiewu Psalmu 51, po którym odmawia się hymny, prāemiā, sedrā i etrā oraz cały szereg czytań biblijnych: Wj 34,18-26; 2 Krl 23,2125; Iz 5,4-10; 1P 3,17-22; Hbr 10,21-29. Następnie jeden z obecnych kapłanów odczytuje fragment z J 13,1-19. Podczas odczytywania czwartego wersetu („wstał od wieczerzy i złożył szaty. A wziąwszy prześcieradło nim się przepasał") opat powstaje ze swego miejsca, zdejmuje wierzchnią część habitu, zakłada fartuch i błogosławi uprzednio przygotowaną wodę. Po modlitwie kapłan odczytuje kolejny werset $\mathrm{z}$ Ewangelii, po którym jeden z mnichów wciela się w postać św. Piotra. Gdy przełożony podchodzi do niego, by umyć mu nogi, rozpoczyna się między nimi ewangeliczny dialog (J 13,6-10):

Podszedł więc do Szymona Piotra, a on rzekł do Niego: «Panie, Ty chcesz mi umyć nogi?» Jezus mu odpowiedział: «Tego, co Ja czynię, ty teraz nie rozumiesz, ale później będziesz to wiedział». Rzekł do Niego Piotr: «Nie, nigdy mi nie będziesz nóg umywał». Odpowiedział mu Jezus: «Jeśli cię nie umyję, nie będziesz miał udziału ze Mną». Rzekł do Niego Szymon Piotr: «Panie, nie tylko nogi moje, ale i ręce, i głowę!». Powiedział do

\footnotetext{
27 B. Varghese, Holy Week Celebrations, s. 176.

28 Por. A. Kakkanatt, Christological Catechesis, s. 41.

29 Tamże.
} 
niego Jezus: «Wykąpany potrzebuje tylko nogi sobie umyć, bo cały jest czysty. I wy jesteście czyści, ale nie wszyscy».

Po zakończonym obrzędzie umywania nóg rozpoczyna się uroczysta celebracja eucharystyczna, po której następuje nabożeństwo zbudowane z modlitw opartych na pobożności ludowej indyjskich chrześcijan.

Wśród chrześcijan św. Tomasza wykształcił się jeszcze inny zwyczaj, zwany Pesaha ${ }^{30}$, który w swej treści i wymowie nawiązuje do żydowskiego świętowania Paschy. Dotyczy on świętowania tych wyjątkowych wydarzeń paschalnych w gronie rodziny. Ogólna zasada mówi, że w dniu celebracji domostwo powinno zostać wysprzątane przez głowę rodziny - w większości keralskich rodzin funkcję tę pełni ojciec. Istotnym elementem tej czynności jest usunięcie z domostwa jakiegokolwiek kawałka kwaszonego chleba. W nawiązaniu do zwyczaju żydowskiego, który mówi o przygotowaniu talerza zawierającego sześć symbolicznych pokarmów, indyjscy chrześcijanie przygotowują specjalny posiłek pozbawiony jakiegokolwiek śladu fermentacji, nazywany Pesaha appam (lub Kurish-appam). Ponadto na ten właśnie wieczór przygotowywany jest słodki napój zwany paal, który ma zastępować wino. Appam upieczony jest ze specjalnego rodzaju białej soczewicy, mąki, czosnku, lokalnych ziól, orzecha kokosowego oraz pobłogosławionych w Niedzielę Palmową liści palmowych. Z kolei paal przygotowuje się z mąki ryżowej, mleka kokosowego, cukru trzcinowego i ziół ${ }^{31}$.

Sam obrzęd sprawowany jest w rodzinach w wielkoczwartkowy wieczór. Zarówno appam, jak i paal podaje się w nowych naczyniach bądź w specjalnych, używanych raz w roku tylko przy tej okazji. Podczas posiłku odczytuje się tekst Księgi Wyjścia i - w niektórych przypadkach - także fragment Nowego Testamentu z narracją opisującą Ostatnią Wieczerzę. Po zakończonym posiłku rodziny często śpiewają hymny i psalmy,

${ }^{30}$ Słowo pesaha pochodzi z syryjskiego słowa peșha, które wywodzi się z hebrajskiego pesah oznaczającego „paschę”. Słowo to zapisane w transliteracji jest powszechnie używane przez chrześcijan św. Tomasza na określenie Wielkiego Czwartku. Wskazuje ono na spożywany tego dnia posiłek paschalny.

${ }^{31}$ Por. S. G. J. Alumkal, Pesaha Tradition of Saint Thomas Christians of India, „Parole de l'Orient” 40 (2015), s. 56-58. 
co czyni indyjską paschę jeszcze bardziej podobną do jej żydowskiego pierwowzoru $^{32}$.

\section{WIELKI PIĄTEK}

Celebracje Wielkiego Piątku, nazywanego przez Keralczyków „Piątkiem Bólu”, wydają się jednymi z najbardziej poruszających w łonie całego chrześcijaństwa. Przepisane na ten dzień oficja, hymny, modlitwy i gesty skoncentrowane są na jedynej racji tego dnia - krzyżu Jezusa Chrystusa. Mimo że syryjska liturgia Wielkiego Piątku ukształtowała się pod silnym wpływem obrzędów jerozolimskich i jest bodaj najbardziej dramatyczną wersją wielkopiątkowych celebracji poza Świętym Miastem, w Indiach obrzędy te zyskały wyjątkowy i niepowtarzalny charakter ${ }^{33}$.

Charakterystyczną cechą syromalankarskich ceremonii Wielkiego Piątku jest ich długość. Rozpoczynają się one zazwyczaj około godziny ósmej rano i trwają przez następnych siedem bądź osiem godzin z krótką przerwą na przygotowany dla wszystkich postny posiłek. W wielkopiątkowej liturgii uczestniczy zazwyczaj znaczna część wspólnoty parafialnej: wierni obecni są od początku do końca.

Liturgia Wielkiego Piątku złożona jest głównie ze śpiewu godzin kanonicznych i czterech specjalnych celebracji odnoszących się do tajemnicy krzyża. Cały dzień naznaczony jest licznymi prostracjami i pełnymi bólu śpiewami. Na zakończenie tercji duchowni wkładają stroje liturgiczne i rozpoczyna się pierwsza procesja, która symbolizuje drogę krzyżową Jezusa Chrystusa ${ }^{34}$. Na rozpoczęcie tejże procesji ubrany w czarny płaszcz przewodniczący liturgii nakłada na prawy bark białe płótno. Następnie owija $\mathrm{w}$ nie zdjęty uprzednio ze statywu krzyż i niesie go, naśladując

32 Tamże, s. 59. Więcej zob. A. G. Kollamparampil, The Pesha Celebration in the Families of St Thomas Christians of India, „Ecclesia Orans” 13 (1996), s. 75-85; T. Koonammakkal, The Passover Celebration of the Mar Thoma Nazranis, „Parole de l'Orient" 41 (2015), s. 223-238.

33 Więcej na temat wpływu wielkopiątkowych celebracji Jerozolimy na inne liturgie zob. I. H. Dalmais, Une relique de l'antique liturgie de Jérusalem. L'Office de l'Ensevelissement du Christ au soir du Vendredi-Saint, „Orient Syrien” 6 (1961), s. 441-454.

34 Por. A. Kakkanatt, Christological Catechesis, s. 42. 
Chrystusa dźwigającego krzyż na Golgotę. Gdy procesja powraca do kościoła, krzyż odkłada się z powrotem na mnārthā, zgromadzeni wierni odmawiają dwie kolejne godziny brewiarzowe ${ }^{35}$, a po nich rozpoczyna się kolejna ważna ceremonia, tj. adoracja krzyża. Ta część liturgii ma następującą strukturę: modlitwa wprowadzająca; śpiew Psalmów 51, 22 i 69; Magnificat; Psalm 113; błogosławieństwa; antyfony; czytanie ze Starego Testamentu; Epistoła; proklamacja czterech fragmentów Ewangelii: Łk 23,49; Mt 27,55-57; Mk 15,41; J 19,31-37; ofiara kadzielna ${ }^{36}$. Następnie kapłan odśpiewuje antyfonę: „Kłaniamy Ci się, o Krzyżu, przez który otrzymaliśmy zbawienie naszych dusz i wraz z łotrem wołamy: pamiętaj o nas, Chryste, gdy przyjdziesz" ${ }^{37}$. Po tych słowach zgromadzeni duchowni, służba ołtarza oraz wszyscy wierni (najpierw mężczyźni, po nich kobiety) podchodzą do stopni sanktuarium, aby ucałować złożony na nich krzyż. Podczas adoracji krzyża wnętrze świątyni wypełnione jest dymem kadzielnym, który oznacza zarówno zejście Chrystusa do otchłani, jak i ciszę pogrążonego w żałobie świata. Po zakończeniu osobistej adoracji wiernych kapłan ponownie wkłada na swe ramiona białe płótno, bierze krzyż i rozpoczyna się druga procesja (Sleebaayaa ghosham) wewnątrz kościoła: dwukrotnie zgodnie z ruchem wskazówek zegara i raz w przeciwnym kierunku. Symbolicznie ukazuje ona zdjęcie ciała Chrystusa z krzyża przez Józefa z Arymatei i Nikodema. Procesja ta czterokrotnie się zatrzymuje i wówczas przewodniczący odmawia następujące modlitwy:

- przy wschodniej ścianie świątyni: „Chryste, nasz Panie, który zostałeś ukrzyżowany dla zbawienia naszego plemienia. Spraw, by Twój Święty Krzyż był nadzieją naszego pokoju, znakiem naszego zwycięstwa i orężem naszego zbawienia. Zachowaj nas po jego stronie i chroń nas siłą jego zwycięstwa nasz Panie i odwieczny Boże, na wieki wieków"38;

- przy zachodniej ścianie kościoła: „Panie, nasz Boże! Pozwól owcom Twej parafii stać się godnymi ochrony przed złymi planami diabła i nikczemnymi zamiarami niegodziwców dzięki pieczęci Twego zwycięskiego

\footnotetext{
35 Por. P.A. Kadavil, The Syrian Orthodox Church, s. 95.

36 Por. B. Varghese, Holy Week Celebrations, s. 181.

37 ktābādmiaddānā, s. 306.

${ }^{38}$ Holy Liturgy of Passion Week, s. 189; ktābādmiaddānā, s. 310.
} 
Krzyża. O Chryste, jedyny prawdziwy Pasterzu umęczony dla naszej sprawy, wysławiamy Cię i chwalimy na wieki wieków"39;

- przy północnej ścianie świątyni: „Spraw Panie, byśmy mogli oddać prawdziwy kult, w duchu i prawdzie, Twojemu czcigodnemu i zwycięskiemu życiodajnemu Krzyżowi. Pobłogosław nas łaską radosnego i pełnego nawrócenia śpiewu i czystego serca przed znakiem Twego świętego Krzyża. Niech wierni Kościoła, którzy go [Krzyż] wychwalają, wyzwoleni będą od raniących nieprzyjaciól, a ich dzieci niech będą zachowane od wszelkich niebezpieczeństw. O Chryste, nasz Boże, który zostałeś ukrzyżowany dla zbawienia całego świata, składamy Ci cześć i chwałę, teraz i na wieki" ${ }^{40}$;

- przy południowej ścianie świątyni: „O Panie, niech Twój święty Krzyż będzie największym orężem zbawienia Twojego świętego Kościoła i niepokonaną zbroją do walki z jego nieprzyjaciółmi, którzy stają przeciwko niemu. Niech pasterze i nauczyciele świętego Kościoła przez Twój Krzyż zostaną oświeceni w mocy Ducha Świętego. Niech jego kapłani i diakoni służą Ci w czystości; niech królowie i żołnierze żyją w pokoju i cichości, a wszyscy wierni niech otrzymają bogate błogosławieństwo Twej łaski. Składamy cześć i dziękczynienie Tobie, Twemu Ojcu i Twemu Świętemu Duchowi teraz i na wieki”"41.

Po zakończonej procesji celebrans staje przed sanktuarium i zwrócony w stronę Wschodu uniesionym do góry krzyżem błogosławi cztery strony świata ${ }^{42}$. Błogosławieństwo to ma formę responsoryjną, podobnie jak w Niedzielę Palmową ${ }^{43}$.

Ostatnią częścią wielkopiątkowych obrzędów jest „pogrzeb krzyża”. Główny celebrans stojąc przed ołtarzem, przygotowuje mieszankę octu z mirrą. Następnie namaszcza cztery krawędzie krzyża i obmywa go różaną wodą, co symbolizuje obmycie ciała Chrystusa przed złożeniem do grobu. Następnie kilka ziaren kadzidła umieszcza się na ramionach krzyża i przykrywa się je czystą bawełną. Tak przygotowany krzyż owija się białym płótnem, które z kolei związuje się liśćmi poświęconych w Niedzielę Palmową palm. Następnie celebrans przenosi krzyż do symbolicznego

\footnotetext{
39 Holy Liturgy of Passion Week, s. 190; ktābādmáddānā , s. 310.

${ }^{40}$ Holy Liturgy of Passion Week, s. 192; ktābādmiaddānā, s. 312.

${ }^{41}$ Holy Liturgy of Passion Week, s. 193; ktābādmaddānā, s. 314.

${ }^{42}$ B. Varghese, Holy Week Celebrations, s. 181.

${ }^{43}$ Zob. tamże, s. 182.
} 
grobu znajdującego się w niszy za ołtarzem, gdzie składa go w sposób niezwykle delikatny i właściwy, tzn. górna część krzyża zwrócona jest w stronę południową, a prawa strona w stronę północną, by w ten sposób dotknięty został przebity włócznią bok Pana Jezusa ${ }^{44}$.

Przed opuszczeniem kościoła każdy uczestnik liturgii otrzymuje od kapłana łyk gorzkiego napoju przygotowanego z mieszanki specjalnie dobranych ziół, który ma przypominać o męce i cierpieniu Pana ${ }^{45}$.

Nazajutrz, w sobotni poranek, zazwyczaj odprawia się liturgię eucharystyczną „za tych, co w Szeolu”. Ta praktyka nie wiąże się z żadnymi specyficznymi tradycjami indyjskimi, ale przywołuje starożytną intuicję Kościoła, wedle której w cichości Wielkiej Soboty Chrystus zszedł obudzić spoczywających w odmętach otchłani ${ }^{46}$.

\section{LITURGIA ZMARTWYCHWSTANIA}

W starożytnym łacińskim hymnie Exultet wielkość tajemnicy paschalnej wysławiana jest m.in. takimi słowami: $O$ vere beata nox, quoe sola meruit scire tempus et horam, in qua Christus ab infernis resurrexit ${ }^{47}$ ! Ten krótki werset zwraca uwagę na fakt, że zmartwychwstanie Chrystusa nie było wydarzeniem spektakularnym, ale pozbawione było rozgłosu i zatopione w cichości nocy. W Indiach bardzo często ten tajemniczy moment powiązany jest z misteriami, w których w niezwykle plastyczny i fonetyczny sposób przedstawia się fakt i moment zmartwychwstania (dotyczy to zwłaszcza wspólnot większościowego tu Kościoła syromalabarskiego).

Jednakże w liturgicznym obrządku syromalankarskim po odmówieniu wielkosobotnich wieczornych godzin kanonicznych celebruje się prawdziwie pokój i ciszę zmartwychwstania. W stanowiącej kanwę niniejszego studium parafii Anchery Wigilia Paschalna rozpoczyna się około godziny 22. Warto dodać, że sąsiadująca z nią wspólnota syro-ortodoksyjna rozpoczyna swoje celebracje zgodnie $z$ dawną tradycją o godzinie trzeciej w nocy. W pewnym momencie podczas odśpiewywania psalmów

\footnotetext{
44 A. Kakkanatt, Christological Catechesis, s. 43.

${ }^{45}$ B. Varghese, Holy Week Celebrations, s. 183.

${ }^{46}$ Zob. Epiphanius, [Dubia aut spuria], PG 43, k. 439, 451, 462-463.

${ }^{47}$ Missale Romanum. Iuxta typicam tertiam, Città del Vaticano 2008, s. 278.
} 
i hymnów celebrans wraz z usługującymi wchodzi do sanktuarium i udaje się do symbolicznego grobu Chrystusa. Po wyjęciu z niego Krzyża obmywa się go wodą i dekoruje czerwoną jedwabną szarfą, stanowiącą rodzaj łacińskiej stuły bądź syryjskiego hamnikhā czy greckiego epitrachelionu ${ }^{48}$. Następnie celebrans, trzymając Krzyż, mówi: „Najmilsi, obwieszczam wam nową wieść: Chrystus powstał z grobu i pokonał nieprzyjaciół”. Zgromadzony lud odpowiada: „Prawdziwie wierzymy i wyznajemy”. Ów dialog powtarza się trzykrotnie ${ }^{49}$.

Następnie odmawia się dalszą część oficjum, po którym następuje uroczysta procesja wokół kościoła. Zależnie od okoliczności procesja okrąża świątynię raz bądź trzykrotnie. Warto zaznaczyć, że jest to autentyczny akt kultu, uwidaczniający się w typowej dla Indii wielości parasoli i kolorów. W trakcie procesji śpiewany jest niezwykle ważny syryjski hymn „O Mario, jestem ogrodnikiem” (O Maryam 'enaw ganāna $\bar{a}^{50}$ ). Po powrocie do kościoła następuje obrzęd pokoju. Kapłan, trzymając krzyż, błogosławi cztery strony świata; ów obrzęd przybiera niezwykle uroczystą formę i by uczynić zadość indyjskiej wrażliwości - odprawiany jest bardzo głośno. Następnie duchowieństwo przekazuje sobie nawzajem i wiernym znak pokoju, po czym - w atmosferze radości - rozpoczyna się adoracja krzyża „uwielbionego”. Ostatnim aktem celebracji jest uroczysta liturgia eucharystyczna. Warto dodać, że w Kerali niemal każda ważniejsza uroczystość kościelna połączona jest z posiłkiem oferowanym całej wspólnocie. Nawet podczas Wigilii Paschalnej, która zazwyczaj kończy się późno w nocy, jest czas na świętowanie przy stole.

Chociaż syromalankarskie celebracje Wielkiego Tygodnia wpisują się we wspólne dziedzictwo całego chrześcijaństwa, to jednak nie ulega wątpliwości, że związana z nimi obrzędowość zyskała tu specyficzny i wyjątkowy indyjski charakter. Dotyczy to różnych aspektów: muzyki, kolorów i emocjonalnego zaangażowania wiernych. Można powiedzieć,

48 Zob. A. Kakkanatt, Christological Catechesis, s. 46-47.

${ }^{49}$ Holy Liturgy of Passion Week, s. 230; ktābādmiaddānā, s. 338

50 Zob. Madrosho of Resurrection. Taksā d-miad'adānā, Pampakuda 1984, s. 485. Na temat teologii syryjskich obrzędów Wielkiej Nocy zob. R. Lanchon, Le temps pascal dans la liturgie syrienne, „Orient Syrien” 7 (1962), s. 337-356. 
że przejęte z Jerozolimy celebracje paschalne zyskały w Indiach zupełnie nową ekspresję, która potwierdza zasadność starego aksjomatu używanego na opisanie istoty tzw. chrześcijaństwa św. Tomasza, który przywołany został na początku niniejszego studium: „hinduistyczne w kulturze, chrześcijańskie w religii i orientalne w kulcie" ${ }^{51}$.

Streszczenie. Wielki Tydzień jest bez wątpienia dla wszystkich chrześcijan szczytem życia liturgicznego. Ponieważ celebracje te swymi korzeniami sięgają Jerozolimy, każda wspólnota posiada szereg tożsamych obrzędów i tradycji. Jednakże mimo tego pozornego uniformizmu różne tradycje liturgiczne wypracowały szereg własnych wyrazów ekspresji wiary celebrowanej w tym najważniejszym dla nich czasie roku kościelnego. Jedną z interesujących i do dziś słabo znanych form kulturowej akomodacji liturgii są bez wątpienia Indie, gdzie chrześcijaństwo istnieje i rozwija się od starożytności. W niniejszym studium podjęto problematykę wielkotygodniowych obrzędów Kościoła syro-malankarskiego, który jest indyjską wersją starożytnej tradycji zachodniosyryjskiej. Zgłębianie obrzędów Wielkiego Tygodnia potwierdza prawdę starodawnego aksjomatu, wedle którego indyjscy chrześcijanie św. Tomasza prawdziwie są: „hinduistyczni w kulturze, chrześcijańscy w religii i orientalni w kulcie”.

Słowa kluczowe: Wielki Tydzień; ryt syromalankarski; liturgia; chrześcijaństwo indyjskie; obrzędy paschalne.

Abstract. Holy Week Celebrations in the West-Syriac Tradition of Syro-Malankara Church in India. Holy Week constitutes the climax of the liturgical life of every Christian community. Having a common base in Jerusalem, different communities shared a common heritage in the celebrations of these special sacred times. But each liturgical family created its own special background for the celebrations. One of the interesting and yet less-known areas of cultural accommodation of the liturgy is without any doubt India, where Christianity existed from the early centuries of Christendom. In this study attention is focused on the Holy Week celebrations of the Syro-Malankara Church, which is a branch of the West-Syriac Tradition. Describing the celebrations one can affirm the truth of the ancient axiom which says that the Suryani Christians in India are "Hindu in Culture, Christian in Religion and Oriental in Worship".

Key words: Holy Week; Syro-Malankara Rite; Liturgy; Indian Christianity; Paschal celebrations.

${ }^{51}$ P. J. Podipara, Hindu in Culture, s. 82. 


\section{BIBLIOGRAFIA}

Acharya F., Prayer with the Harp of the Spirit. The Prayer of Asian Church, t. 3, Kurishumala 1985.

Alumkal S. G. J., Pesaha Tradition of Saint Thomas Christians of India, „Parole de l'Orient” 40 (2015), s. 53-64.

Burkitt F. C., The Jacobite Service for Holy Saturday, „Journal of Theological Studies” 24 (1923), s. 424-427.

Dalamis I. H., Unerelique de l'antiqueliturgie de Jérusalem. L'Office del'Ensevelissement du Christ au soir du Vedredi-Saint, „Orient Syrien” 6 (1961), s. 441-454.

Égerié, Journal de voyage (Itinéraire), trad. et ed. M. C. Díaz y Díaz, V. Bergidensis, P. Maraval, SCh 296, Paris 1982.

Epiphanius, [Dubiaautspuria], PG 43, k. 439-463.

Hebdomadae sanctae celebratio. Conspectus historicus comparativus, ed. A. G. Kollamparampil, BEL Subsidia 93, Roma 1997.

Holy Liturgy of Passion Week: From Hosanna to Kyoto (Easter), Mississauga (ON, Canada) 2011.

Janeras S., La Settimana Santa nellantica liturgia di Gerusalemme, w: ed. A. G. Kollamparampil, Hebdomadae sanctae celebratio. Conspectus historicus comparativus, BEL Subsidia 93, Roma 1997, s. 19-50.

Kadavil P. A., The Syrian Orthodox Church: its Religion and Philosophy, Kottayam 2005.

Kakkanatt A., Christological Catechesis of the Liturgy. A Study on the Great Feasts of our Lord in the Malankara Church, Rome 1996.

Kollamparampil A. G., The Pesha Celebration in the Families of St Thomas Christians of India, „Ecclesia Orans” 13 (1996), s. 75-85.

Konat A., ktābā d-taksā d-husāye d-shabtā d-hashā pārukāyā da mshiā alāhan, Pampakkuda 1958.

Koonammakkal T., The Passover Celebration of the Mar Thoma Nazranis, „Parole de l'Orient" 41 (2015), s. 223-238.

Ktābādmiaddānā d-hudrā shantānāyā, Andu Thaksā (Suriyani, Malayalam), Puthencurz 2016.

Ktōbō d-slutō d-sabtō rabtō pōrukōyō, Kottayam 1930.

Lanchon R., Les temps pascal dans la liturgie syrienne, „Orient Syrien” 7 (1962), s. 337-356.

Madroshoof Resurrection. Taksā d-miad’adānā, Pampakuda 1984.

Pallath P., La Chiesa cattolica in India, Roma 2011.

Pallath P., Syro-Malankara Catholic Church, w: E. G. Farrugia, Encyclopedic Dictionary of the Christian East, Rome 2015, s. 1780-1783.

Palm Sunday (Kuruthola Perunnal), Maundy Thursday (Pesaha), Good Friday (Dukha Veli) and Easter among Saint Thomas Christians of India, http://www.nasrani. net/2007/03/25/passover-among-nasrani-syrian-christians-of-kerala/ (10.02.2017). 
Podipara P. J., Hindu in Culture, Christian in Religion and Oriental in Worship, „Ostkirche Studien" 8 (1959), s. 82-104.

Potoczny M., Kościół dla wybranych? O specyfice indyjskich chrześcijan knānāya, „Teologia i Człowiek" 28 (2014) 4, s. 237-257.

Prayers of the Holy Week, ed. B. Varghese, Kottayam 2015.

Righetti M., Storia liturgica, t. 2, Milano 1969.

Roberson R., Malankara Jacobite Syrian Orthodox Church, w: E. G. Farrugia, Encyclopedic Dictionary of the Christian East, Rome 2015, s. 1185-1186.

Roberson R., Malankara Orthodox Syrian Church, w: E. G. Farrugia, Encyclopedic Dictionary of the Christian East, Rome 2015, s. 1186-1188.

Schmemann A., A Liturgical Explanation of Holy Week, http://orthodoxinfo.com/general/a-liturgical-explanation-of-holy-week.pdf (12.04.2017).

Sebastian C. D., Saint Thomas Christians of India: A Paradigm of Cultural Identity in the Eastern Christianity, w: Philosophy, Religion, and Culture of Asian Countries, ed. S. Pakhomov, Saint-Petersburg 2009, s. 130-137.

Varghese B., Holy Week Celebrations in the West Syrian Church, w: Hebdomadae sanctae celebratio. Conspectus historicus comparativus, ed. A. G. Kollamparampil, BEL Subsidia 93, Roma 1997, s. 165-186.

Varghese B., West Syrian Liturgical Theology, Aldershot 2004. 